\title{
Design of Korean Standard Modular Buoy Body Using Polyethylene Polymer Material for Ship Safety
}

\author{
Young Whan Park¹, Tae Wan Kim¹, Jae Sub Kwak¹, In Kwan Kim², Ji Eon Park³, \\ Kyong Ho Ha ${ }^{1}$ \\ ${ }^{1}$ Department of Mechanical Engineering, Pukyong National University, Busan, Korea \\ ${ }^{2}$ Department of R \& D, Newmarine Engineering co., Ltd., Busan, Korea \\ ${ }^{3}$ Department of Electric Energy, Dongwon Science and Technology University, Busan, Korea \\ Email: parkyw@pknu.ac.kr
}

Received 20 October 2015; accepted 5 January 2016; published 11 January 2016

\begin{abstract}
Buoy is the structure which is floated on sea surface in order to indicate the presenting obstacle such as reef and shallow sea and to show the direction of sea route to ship during sailing. Generally, the conventional material of buoy is steel and it has some problems. Firstly this steel light buoy has safety risk in case of collision between ship and steel buoy. Secondly steel buoy revealed high corrosion environment of salted water and oxide and corrosion of steel can lead to marine pollution. Thirdly it needs too much maintain cost because of its heavy weight. In this study, in order to overcome these problems we changed the buoy material from conventional steel body to polyethylene body. Polymer buoy body was designed with module type part and it can reduce total weight up to $43.12 \%$. To evaluate the strength of that part, the structure analysis simulation was carried out with respect to stress, displacement, and strain. Maximum stress was $1.667 \times 10^{7} \mathrm{~N} / \mathrm{m}^{2}$ and it was $25 \%$ of yielding stress of base material. Maximum displacement and strain were 3.164 $\mathrm{mm}$ and 0.00433353 and they are too small value and in safe range with comparing to total length of body. The stability of polymer buoy body was compared with conventional buoy with respect to center of gravity, center of buoyancy, metacenter, oscillation period, and tilt angle by wind, tidal current, and wave. Every value was improved comparing conventional one and we can get more stable buoy. Therefore the new polymer buoy body could prove its safety and stability.
\end{abstract}

\section{Keywords}

Polymer Buoy, Polyethylene Float, Weight Reduction, Structure Analysis, Stability Evaluation

\section{Introduction}

Buoy is the structure which is floated on sea surface and fixed by weight at seabed in order to indicate the presenting obstacle such as reef and shallow sea and to show the direction of sea route to ship during sailing. Gen- 
erally, the conventional material of buoy is steel. Steel buoy has a lot of advantages such as high strength and easy manufacturing using cutting and welding process to make shape. However, it has some problems. Firstly this steel light buoy has safety risk in case of collision between ship and steel buoy. Secondly steel buoy revealed high corrosion environment of salted water and oxide and corrosion of steel can lead to marine pollution. Thirdly it needs too much maintain cost because of its heavy weight. In order to overcome these problems, many researches have been conducted.

Many countries have recognized the problem and limitation of steel buoy for long time and they have tried to study and make new material buoy which are light and environmental friendly. French Government [1] carried out plastic buoy project in 1995 which was substitute the steel buoy, and in America the study of polymer material and module type buoy was conducted through Short Range Aids to Navigation Research of USCG (United State Coast Guide) [2].

In Korea, government studied and analyzed the trend of buoy material through basic research and design work of low cost and environmental friendly buoy development and suggested the development direction of it [3]. Base on this result, Korea government was tried to make new buoy which are functionally advanced, light weight, safe, and special purpose buoy [3]. Ko [4] and Moon [5] studied polymer buoy and checked feasibility of polymer material application. Kim et al. [6] studied and analyzed the performance of plastic buoy characteristic and Shin et al. [7]-[9] tried to development of plastic float body filled with polyethylene or urethane foam. Park [10] studied to produce small buoy with plastic material applicable Korea sea cost.

In this study, we designed and developed the buoy material from conventional steel body to polyethylene body. Polymer buoy body was designed with module type part. In order to evaluate the strength of that part, the structure analysis simulation was carried out with respect to stress, displacement and strain. To apply this new buoy to sea coast, the performance of buoy with polymer float body should be check with respect to stability. The stability of polymer buoy body was compared with conventional buoy in terms of center of gravity, center of buoyancy, metacenter, oscillation period, and tilt angle by wind, and tidal current.

\section{Korean Standard Buoy}

Korean government defined 11 standard light buoys which can be installed differently according to location, sea wave, and water level and they must be designed and fabricated followed by the law of "Standard buoy manufacturing and quality maintenance". Figure 1 shows the example of Korean Standard LL-26(M) light buoy. It has $9776 \mathrm{~m}$ length and $6054 \mathrm{~kg}$ weight.

As shown in Figure 1, Korean Standard LL-26(M) light buoy consists of sinker, buoy, and mooring chain. Buoy is composed by float, mast with marine lantern, steel structure, and adjustable ballast. Float body supports the mast not to sink into sea and it is the core part of buoy. Steel structure and adjustable ballast take a role of balancing the buoy and they prevent to shake due to wave and wind. Mast has light and it notifies the presenting obstacle such as reef and shallow sea and the direction of sea route to ship during sailing.

Float has the largest contact area with sea in buoy and its shape is airtight container type. Therefore it is made through cutting, bending, and welding process of steel conventionally. In this study, we changed the float body material from conventional steel body to polyethylene body. Plastic float has a lot of advantages: it is lighter than steel material, it is easy to make using forming process with mold die and suitable to mass production, it is simple to assemble and maintenance, and it can minimize damage in case of collision between buoy and ship.

\section{New Buoy Design}

\subsection{Shape of Buoy with Polymer Float Body}

Design for light weight buoy with plastic float body was carried out using SOLIDWORKS 3D CAD program. The target was Korean Standard LL-26(M) buoy which are most widely used in Korean sea coast. Figure 2 and Figure 3 show the new designed buoy. In current steel buoy, float body is mainly changed from steel to polymer and its material was polyethylene (PE) as shown in Figure 3. For steel buoy, float body was 1 part shape in Figure 1. We also changed and designed module type float body consists of 6 modules. It makes us easy to assemble and maintenance buoy. Masts were designed to be fabricated type to maximize the effect of module body.

Table 1 show the comparison between conventional steel buoy and new polymer buoy. As you can see in table, mast and steel structure kept steel material so there is no big weight difference. However, float and ballast 


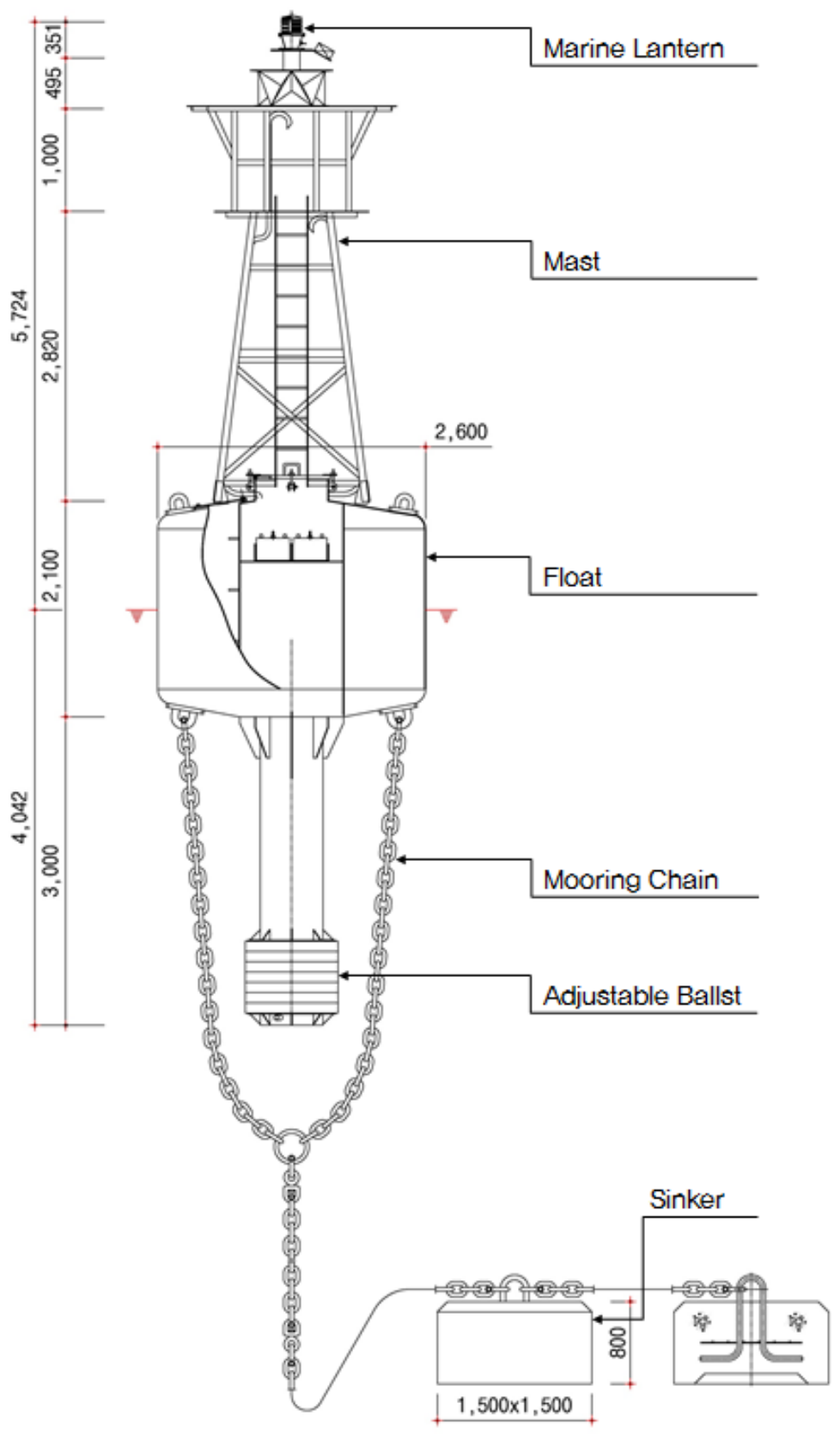

Figure 1. Korean Standard Buoy LL-26(M).

weight could obtain high weight reduction: float body lessen weight down to $32.8 \%$ and ballast was $63.7 \%$. The number of ballast could be decreased because float body weight was reduced. Total weight ratio between steel and polymer buoy is $55.9 \%$ and total weight reduction rate was $44.1 \%$.

\subsection{Float Body Structure Analysis}

In order to evaluate and confirm the safety of new designed float body, we simulated structure analysis base on acting load on plastic float body. Figure $\mathbf{4}$ shows the 3D shape and mesh for simulation. Loaded forces are generally acting on hooks which connect float body and upper tower. Arc center of float body is fixed to steel structure. It could be boundary condition of simulation. At Table 1, float body weight was $948 \mathrm{~kg}$ and it is divided 6 modules, so 1 module weight is $158 \mathrm{~kg}$. But we set the loaded force as $200 \mathrm{~kg}$ considering the safety. 

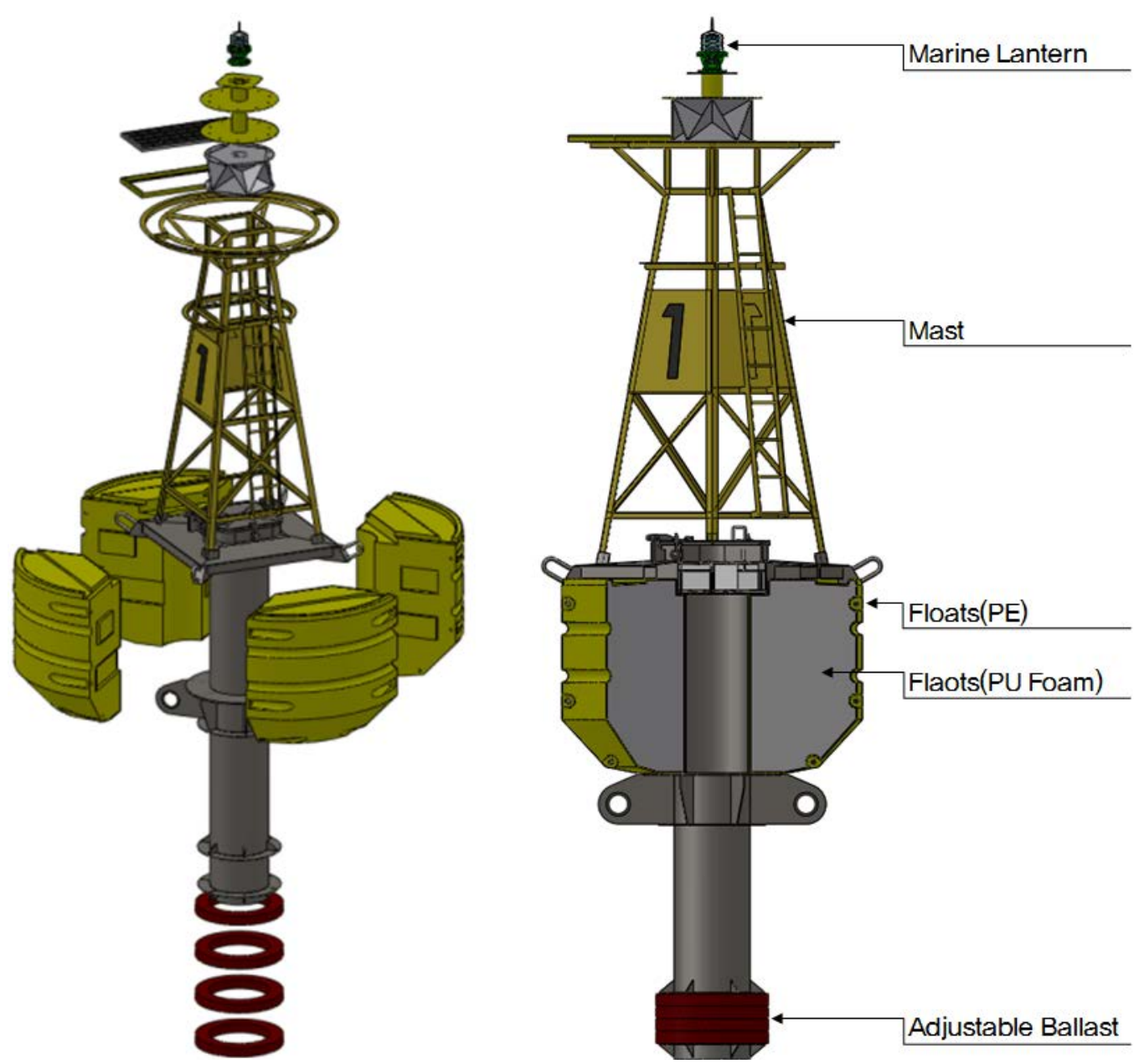

Figure 2. Example of Korean Standard Buoy using polymer float.
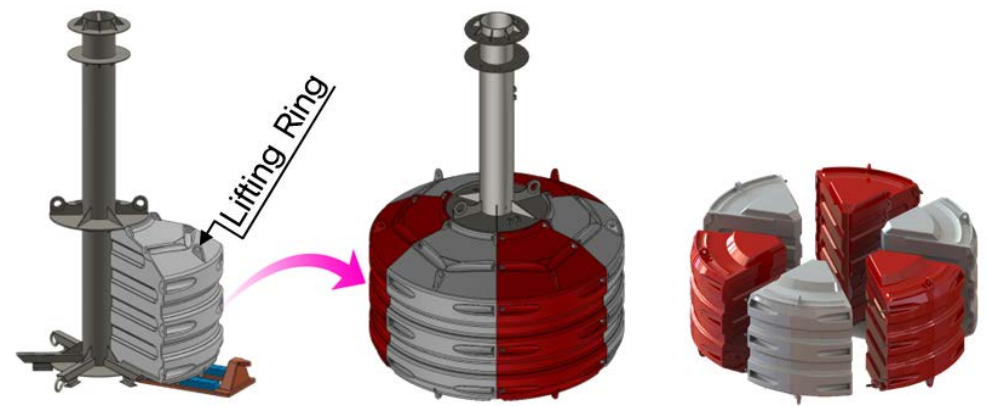

Figure 3. New designed 6 modules of float and its assembly method.

Table 1. Ratio of light weight of new designed PE buoy

\begin{tabular}{cccc}
\hline Parts & Conventional Buoy $(\mathrm{kg})$ & New Designed Buoy $(\mathrm{kg})$ & Ratio of weight $(\%)$ \\
\hline Float & 2891 & 948 & 32.8 \\
Mast and Steel Structure & 1215 & 1220 & 100.4 \\
Ballast & 1637 & 1043 & 63.7 \\
Total Weight & 5743 & 3211 & 55.9 \\
\hline
\end{tabular}




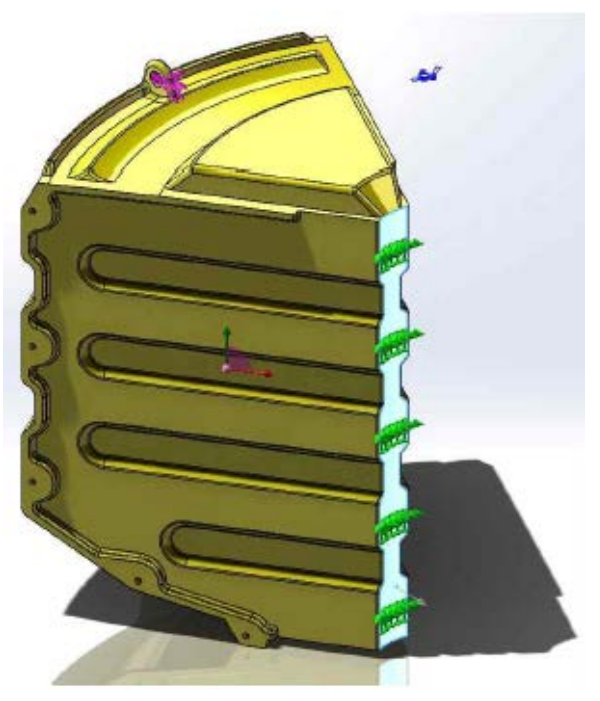

(a)

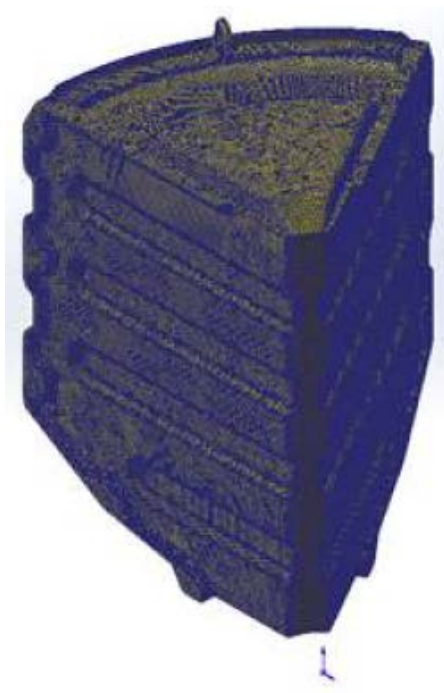

(b)

Figure 4. Modeling and mesh with load and constrain for structure analysis simulation.

The material properties of PE float are shown in Table 2. Mesh for structure analysis was individual mesh, total material point number of mesh was 1,154,932 and total element was 673,432. Maximum size of element was 15 $\mathrm{mm}$ and minimum was $5 \mathrm{~mm}$

The structure analysis was simulated in terms of stress, displacement, and strain. The results of simulation were in Figure 5. In Figure 5, (a) show the stress result. The local maximum stress was $4.24199 \times 106 \mathrm{~N} / \mathrm{m}^{2}$ at hook point which are about $25.44 \%$ of yielding stress of material in Table 2. It means that float body could secure 4 times of safety factor and it is safe. Figure 5(b) shows the displacement result and maximum displacement was $3.16441 \mathrm{~mm}$ at hook. Considering the size of body which is $1880 \mathrm{~mm}$ height and $1500 \mathrm{~mm}$ radius, this displacement could be ignorable. Figure 5(c) shows that maximum strain was 0.00433353 . It is very small value. Because PE material has good elastic characteristic, strain will be restored as soon as the loading force is removed. Consequently, the safety of new designed polymer float body is proved base on structure analysis simulation.

\section{Stability Evaluation of New Designed Buoy}

In order to evaluate the stability of new designed buoy with polymer float body, we compared the characteristics between conventional buoy and new buoy in terms of center of gravity, center of buoyancy, metacenter, period of motion, and inclination angle. As the input parameter, we assumed extreme natural condition: sea depth was $20 \mathrm{~m}$, sea wave period was $10 \mathrm{sec}$, sea wave height was $5 \mathrm{~m}$, and tidal current was $5 \mathrm{kts}$. Final results and calculation was referred to handbook of the navigation beacon [11].

\subsection{Center of Gravity: KG}

Center of gravity of new designed buoy could be calculated by weight distribution for all element frames. Total weight of all element was $3211 \mathrm{~kg}$ as shown in Table $\mathbf{1}$ and the first moment of weight was $562.6 \mathrm{~kg}_{\mathrm{f}} \cdot \mathrm{m}$ in this study. Center of gravity could be obtained with Equation (1).

$$
K G=M_{C} / W=562.6 / 3211=0.175 \mathrm{~m}
$$

where, $M_{c}$ is the first moment of weight and $W$ is the total weight for buoy.

\subsection{Center of Buoyancy: KB}

Center of buoyancy is defined as the center of submerged volume of buoy. Submerged volume of buoy is equal to displacement which is water volume pushed by buoy. To compute the center of buoyancy, displacement and first moment of drain water volume should be known. The values of them are in Table $\mathbf{3}$ and center of buoyancy 


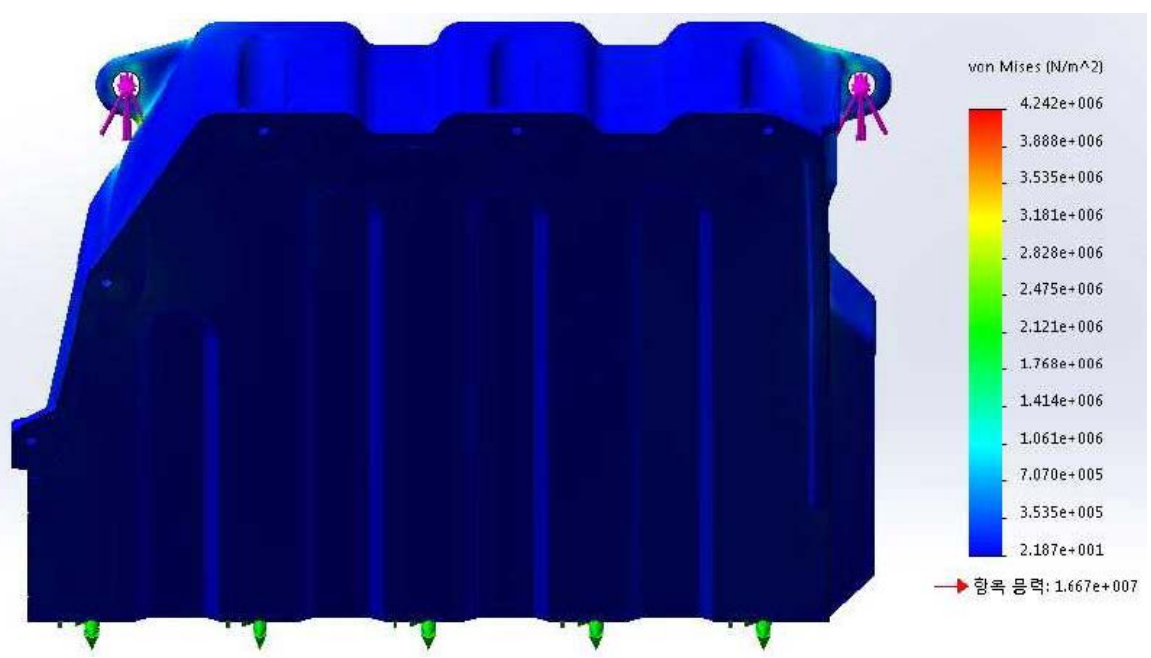

(a)

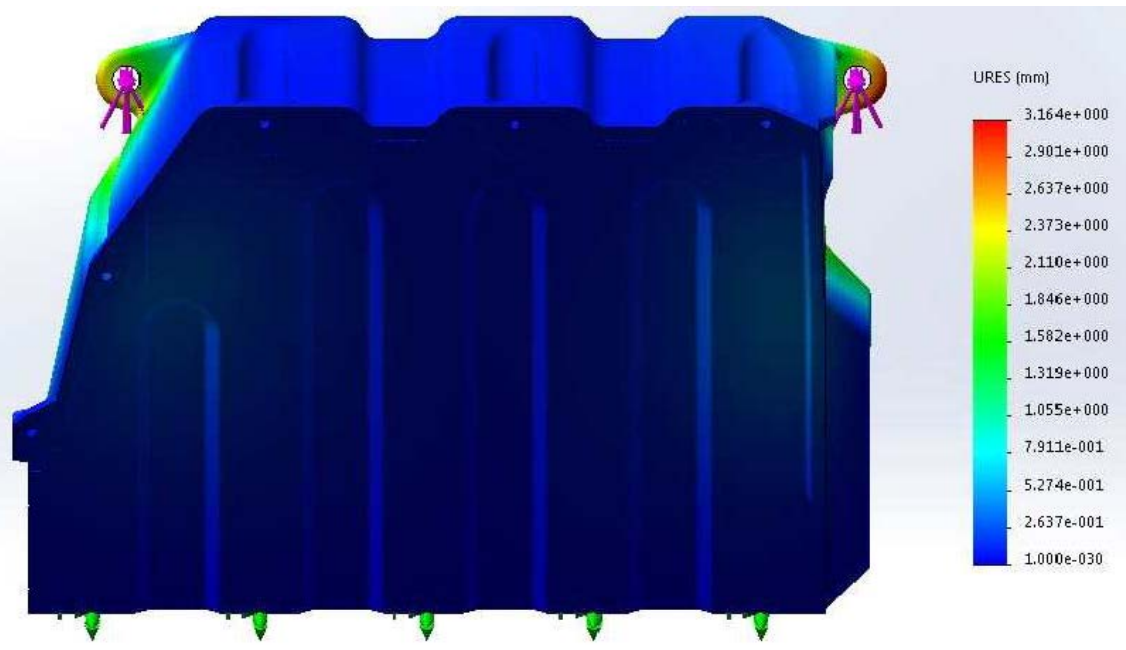

(b)

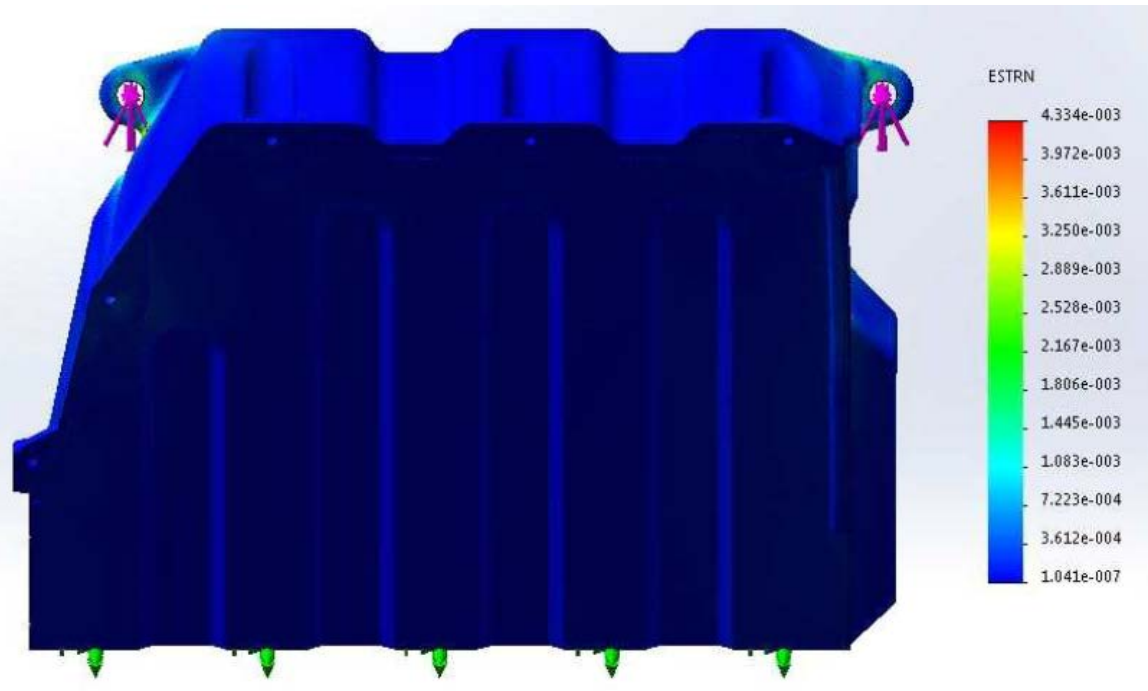

(c)

Figure 5. Result of structure analysis simulation. (a) Von mises stress; (b) Displacement; (c) Equivalent strain. 
Table 2. Material properties for structure analysis.

\begin{tabular}{cccc}
\hline Material Property & Density $\left(\mathrm{kg} / \mathrm{m}^{3}\right)$ & Yielding Stress $\left(\mathrm{N} / \mathrm{m}^{2}\right)$ & Tensile Stress $\left(\mathrm{N} / \mathrm{m}^{2}\right)$ \\
\hline Value & 937 & $1.66714 \times 10^{7}$ & $2.05941 \times 10^{7}$ \\
\hline Material Property & Young's Modulus $\left(\mathrm{N} / \mathrm{m}^{2}\right)$ & Poisson's Ratio & Shear Modulus $\left(\mathrm{N} / \mathrm{m}^{2}\right)$ \\
\hline Value & $7.1 \times 10^{8}$ & 0.439 & $5.94002 \times 10^{7}$ \\
\hline
\end{tabular}

Table 3. Displacement volume and 1st moment of displacement of buoy.

\begin{tabular}{cccc}
\hline Parts & $\begin{array}{c}\text { Displace } \\
\text { Volume }\left(\mathrm{m}^{3}\right)\end{array}$ & $\begin{array}{c}\text { Distance of Datum Line to } \\
\text { Center of Displacement Volume }(\mathrm{m})\end{array}$ & First Moment of Displacement $\left(\mathrm{m}^{4}\right)$ \\
\hline Float Cover & 0.33 & 0.343 & 0.113 \\
Float Air & 2.604 & 1.183 & 3.08 \\
Steel Structure & 0.199 & -1.706 & -0.339 \\
Total & 3.13 & - & 2.854 \\
\hline
\end{tabular}

is in Equation (2).

$$
K B=M_{B} / V=2.854 / 3.13=0.911 \mathrm{~m}
$$

where, $M_{B}$ is the first moment of displacement, and $V$ is displacement volume.

\subsection{Height of Metacenter}

We can define $B M$ as the distance from center of buoyancy to height of metacenter. It effect the period of rolling motion and force of restitution of float body. As the $B M$ value is higher, the buoy is more stable. $B M$ is calculated by Equation (3)

$$
B M=I_{x} / V=3.976 / 3.13=1.269 \mathrm{~m}
$$

where, $I_{x}$ is the moment of inertia for draft of float body and its value is $3.976 \mathrm{~m}^{4}$ in this study. $B M$ is $1.1269 \mathrm{~m}$ as shown in Equation (3).

Also $G M$ is defined as distance from center of gravity to height of metacenter. As the value of $G M$ is greater, the buoy is more stable. GM is calculated by Equation (4) and its value is $2.005 \mathrm{~m}$. Figure 6 shows the position of each stability characteristic value.

$$
G M=B M+K B-K G=1.296-0.911-0.175=2.005 \mathrm{~m}
$$

\subsection{Period of Buoy Motion}

Buoy's oscillation period $\left(t_{0}\right)$ is defined as the back and forth time which float body is vibrated to the center of weight of buoy and it is obtained by Equation (5).

$$
t_{0}=2 \pi \sqrt{\frac{k^{2}}{G M \cdot g}}=2 \pi \sqrt{\frac{2.08^{2}}{2.005 \cdot 9.81}}=2.95 \mathrm{sec}
$$

where, $k$ is the radius of gyration for moment of inertia for additional mass and its value is $2.08 \mathrm{~m}$ and $g$ is acceleration of gravity.

\subsection{Inclination Angle}

Generally inclination angle is generated by wind, tidal current. The inclination angle by wind and tidal current occurred when the moment by wind and tidal current is equal to righting moment. In this study the calculated righting moment by wind applied to buoy was $863.27 \mathrm{~kg}_{\mathrm{f}} \cdot \mathrm{m}$ when the wind speed is supposed to $45 \mathrm{~m} / \mathrm{s}$ and the calculated righting moment by tidal current was $268.434 \mathrm{~kg}_{\mathrm{f}} \cdot \mathrm{m}$ when the speed of tidal current is $5 \mathrm{kts}$. Inclination angle is like Equation (6) as below. 


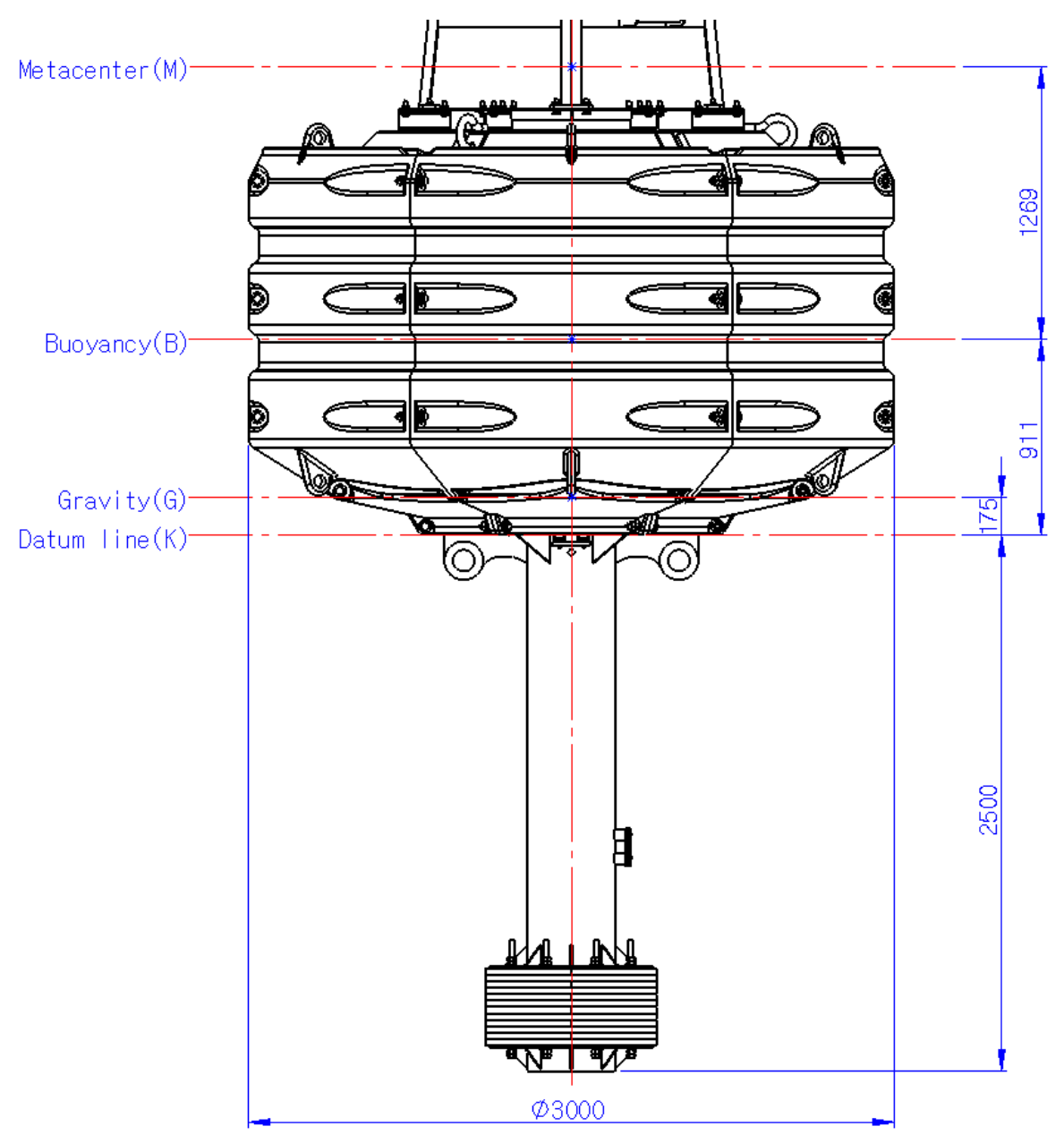

Figure 6. Stability calculations of new designed buoy.

$$
\theta=\sin ^{-1}\left(\frac{M_{R}}{W \cdot G M}\right)
$$

where, $M_{R}$ is righting moment. Using above values, the inclination angle by wind and tidal current is $7.7^{\circ}$ and $2.4^{\circ}$, respectively.

\subsection{Stability Comparison}

Table 4 shows the stability comparison between new designed light buoy and conventional steel buoy. The center of buoyancy for plastic buoy has lower position and righting moment is also higher than these of conventional steel buoy shown in Table 4. In addition the period of motion is shorter than conventional buoy. This means that plastic buoy has better stability than steel buoy. Using Table 4, we can prove that the new designed buoy with plastic float body has good performance and characteristics.

\section{Conclusion}

In this study, we changed the buoy material from conventional steel body to polyethylene. Polymer buoy body was designed with module type part and it can reduce total weight up to $44.1 \%$. To evaluate the strength of that part, the structure analysis simulation was carried out with respect to stress, displacement and strain. Maximum stress was $1.66714 \times 10^{7} \mathrm{~N} / \mathrm{m}^{2}$ and it was $25 \%$ of yielding stress of base material. Max displacement and strain were $3.16441 \mathrm{~mm}$ and 0.00433353 and they are too small value and in safe range with compare to total length of 
Table 4. Stability comparison between conventional and new designed buoy.

\begin{tabular}{cccc}
\hline Stability Parameters & & New Designed Polymer Buoy & Conventional Steel Buoy \\
\hline Center of Gravity & KG & $0.175 \mathrm{~m}$ & $0.281 \mathrm{~m}$ \\
Center of Buoyancy & KB & $0.911 \mathrm{~m}$ & $0.28 \mathrm{~m}$ \\
Distance from KB to metacenter & BM & $1.269 \mathrm{~m}$ & $0.40 \mathrm{~m}$ \\
Distance from KG to metacenter & GM & $2.005 \mathrm{~m}$ & $0.399 \mathrm{~m}$ \\
Period of motion & $t_{0}$ & $2.95 \mathrm{sec}$ & $7.84 \mathrm{sec}$ \\
Inclination angle by wind & $\theta$ & $7.7^{\circ}$ & $19.69^{\circ}$ \\
Inclination angle by tidal current & $\theta$ & $2.4^{\circ}$ & $19.46^{\circ}$ \\
\hline
\end{tabular}

body. The stability of polymer buoy body was compared with conventional buoy. Every value was improved comparing conventional one and it can get more stable buoy. Therefore the new polymer buoy body could prove its safety and stability.

\section{Acknowledgements}

This research is supported by Future Marine Industry Technology Development Project of Korea Institute of Marine Science \& Technology Promotion in 2014 (Project No. 20140162).

\section{References}

[1] Ministry of Land, Transport and Maritime Affairs of Korea (2010) Report for Basic Research and Design Outsourcing of Light and Low Cost Buoy Development.

[2] USCG (2009) Specification No. 450 Revision F on Specification for Fabrication of Ionomer Foam Buys.

[3] Ministry of Land, Transport and Maritime Affairs of Korea (2012) Report for Basic and implementation Design of Mooring Buoy and Special Buoys Research and Development.

[4] Ko, S.K. (2010) Light Buoy with New Materials. Proceedings of Spring Conference for Korean Institute of Navigation and Port Research, 439-441.

[5] Moon, H.S., Cho, K.J., Kim, J.W. and Kang, S.B. (2010) A Study of Plastic Buoy Development. Proceedings of Spring Conference for Korean Institute of Navigation and Port Research, 442-444.

[6] Kim, J.W., Han, J.S., Cho, K.J. and Kang, S.B. (2011) Characteristic Analysis of Plastic Buoy for Navigation Sign. Proceedings of Spring Conference for Korean Institute of Navigation and Port Research, 263-265.

[7] Shin, Y.J. and Jung, T.G. (2010) A Study of Improvement for Buoy and Float Body (I). Proceedings of Fall Conference for Korean Institute of Navigation and Port Research, 19-22.

[8] Shin, Y.J. and Jung, T.G. (2011) A Study of Float Body Improvement of Buoy (Light Buoy) (2). Proceedings of Spring Conference for Korean Institute of Navigation and Port Research, 266-268.

[9] Shin, Y.J. and Jung, T.G. (2012) A Study of Improvement for Buoy and Float Body (II). Proceedings of Fall Conference for Korean Institute of Navigation and Port Research, 407-410.

[10] Park, H.R. (2014) A Feasible Study on the Development of Field Adaptive Mooring Buoy for Small Vessel. Master Thesis, Korea Maritime University, Busan, Korea.

[11] Ministry of Maritime Affairs and Fisheries of Korea (2006) Handbook of the Navigation Beacon. 